\title{
The Relationship Between Tumor Volume and Timing of Post-resection Stereotactic Radiosurgery to Maximize Local Control: A Critical Review
}

\author{
Melissa Yuan ${ }^{1}$, Eltion Behrami ${ }^{2}$, Susan Pannullo ${ }^{1}$, Theodore H. Schwartz ${ }^{3}$, A. Gabriella Wernicke ${ }^{2}$ \\ 1. Neurological Surgery, NewYork-Presbyterian/Weill Cornell Medical Center, New York, USA 2. Radiation Oncology, \\ NewYork-Presbyterian/Weill Cornell Medical Center, New York, USA 3. Neurology, NewYork-Presbyterian/Weill Cornell \\ Medical Center, New York, USA
}

Corresponding author: A. Gabriella Wernicke, gaw9008@med.cornell.edu

\begin{abstract}
After maximally safe neurosurgical resection of brain metastases, stereotactic radiosurgery (SRS) is now recommended as an alternative to whole-brain radiation therapy (WBRT), which has been associated with cognitive decline. One complicating factor associated with SRS is that postoperative cavity dynamics can change dramatically, creating significant variability in the recommended timing of SRS. While SRS has been shown to improve local control (LC) in smaller tumor cavities, achieving excellent LC rates still remains a challenge in larger ones. Furthermore, factors predicting the optimal timing of SRS in relation to the cavity size need to be defined and implemented. Variables such as the delay between postoperative MRI and treatment are critical but poorly understood. One potential treatment option that may improve outcomes is brachytherapy, but the widespread implementation of this technique has been slow. This critical review analyzes the relationship between preoperative tumor volume, resection cavity size, and timing of SRS and explores how these variables must be understood in order to achieve the highest LC possible.
\end{abstract}

Categories: Radiation Oncology, Neurosurgery, Oncology

Keywords: brain metastasis, radiation, local control, stereotactic radiosurgery

\section{Introduction And Background}

Brain metastases may produce tumor mass effect that causes undesirable sequelae including seizures, nausea and vomiting, mental status changes, and other focal neurological defects [1]. Metastases to the brain are typically surgically resected in patients who have three or fewer brain metastases, or who have large tumors causing significant symptoms [2]. The currently accepted standard of care for post-resection treatment is whole-brain radiation therapy (WBRT). WBRT, despite its success in achieving local control (LC) of $\sim 90 \%$, has been associated with intolerably high toxic exposure to the brain and, consequently, decreased cognition and quality of life $[3,4]$.

Received 07/29/2019

Review began 08/05/2019 Review ended 09/17/2019 Published 09/25/2019

๑) Copyright 2019

Yuan et al. This is an open access article distributed under the terms of the Creative Commons Attribution License CC-BY 3.0., which permits unrestricted use, distribution, and reproduction in any medium, provided the original author and source are credited.
Stereotactic radiosurgery (SRS) is a method of delivering high-intensity, focused radiation with the surrounding normal tissue receiving a much lower dose of radiation than the resection cavity itself $[5,6]$. While there is a good deal of promising evidence that SRS can improve LC [5] while sparing the patient toxicity associated with WBRT, it remains difficult to accurately time and target SRS to the resection cavity size, especially in the setting of a larger cavity size/volume. This may be the reason that in some studies, long-term LC has been found to be worse with cavity SRS compared to post-resection WBRT [7,8]. Even so, many studies have shown comparable rates of LC with SRS compared to WBRT for resected brain metastases $[7,9-14]$.

Currently, MRI is used to study the postoperative resection cavity of brain metastases for SRS planning. Part of this planning includes assigning margins to the cavity borders for the administration of the radiation. The challenge is that resection cavities are dynamic and often change unpredictably in shape and size during the interval between the planning of MRI and administering of SRS. This shift in resection cavity dimensions negatively impacts SRS's ability to optimally target areas of residual metastatic tissue while avoiding irradiation of normal tissue.

There have been several studies, both retrospective and prospective, detailing the shifts in resection cavity dimensions at various time points after surgery. In this review, we aim to define the postsurgical resection cavity changes in order to best inform SRS timing to optimize LC, survival time, and quality of life of patients.

\section{Review}

Pubmed and Google Scholar from 2009 to 2019 were searched for articles pertaining to postoperative 
resection-cavity dynamics. Each study was evaluated for the number of patients, cavity-size change findings, cavity size and its influence on LC, and length of follow-up in addition to proposed explanations for observed results. Finally, seven studies that provided data on cavity dynamics after brain metastasis resection within the past 10 years were included.

\section{Post-resection cavity-size changes: does the cavity shrink or grow after surgery?}

The currently available literature indicates that resection cavities are dynamic after surgery. The majority of studies have found that, on average, resection cavities decrease in size postoperatively $[2,15-18]$.

Specifically, Ahmed et al. found that $58 \%$ of post-resection cavities decreased in volume within one month of the procedure [16]. In this sample, 23 out of 39 cavities decreased by $>10 \%$ of their initial dimensions after one month [16]. The authors demonstrated that greater postoperative edema was positively correlated with the subsequent cavity-size decrease in the month after surgery [16]. They found one interesting outlier: a patient with an edema of $>15 \mathrm{~mm}$ who showed a $<10 \%$ decrease in the cavity volume in a follow-up scan in the month after the surgery (since the size of edema was above the postoperative threshold, the imaging should have shown a larger percentage decrease in the cavity volume). However, this follow-up scan was conducted only 11 days after the resection [16]. The authors mention that this outlier patient then had a later MRI at 45 days after surgery, which demonstrated a $27 \%$ decrease in cavity size from the initial postoperative MRI, leading them to conclude that cavities do show a greater decrease in volume given more time [16]. However, as this study did not directly aim to examine cavity dynamics, they did not quantify how cavities across the sample changed over time.

In contrast to Ahmed et al.'s results, Shah et al. found that post-resection edema was not associated with cavity-volume decrease $[16,18]$. Across the sample, Shah et al. demonstrated a $43 \%$ mean decrease in cavity size [18]. This study only had volume data at the immediate postoperative MRI and the planning MRI, with an average of 41 days between [18]. Thus, while the authors were able to determine that patients who underwent imaging within one month of their initial postoperative MRI had a mean cavity-volume decrease of $13 \%$, and those who underwent imaging more than one month after the initial MRI showed a decrease of $61 \%$ [probability value $(\mathrm{p})=0.0003$ ], they were unable to follow the cavity dynamics of each patient over the follow-up period.

Wernicke et al. found that in 30 patients who had had brain metastasis resection, the majority of the patients had cavity-volume decrease with a median cavity shrinkage of $84.8 \%$ at an average follow-up of 50 days [19]. Within each time period, the percentage decrease in size was $-48 \%$ from the immediate postoperative MRI to the first follow-up; -68\% from the immediate postoperative MRI to the second follow-up; and - $85 \%$ from the immediate postoperative MRI to the third follow-up [19]. These percentage changes in cavity volume were statistically significant invariably $(\mathrm{p}=<0.001)$, showing that the cavities steadily continued their decrease in volume after resection.

Scharl et al. found an average cavity-volume reduction of $23.4 \%$ at a median of 23 postoperative days [20]. In line with Wernicke et al.'s results, this study showed a consistent decrease in cavity volume from the first postoperative MRI throughout the follow-up period [20]. The greatest reduction in cavity volume $(-23.4 \%)$ occurred between the immediate postoperative MRI and the planning MRI $(\mathrm{p}=<0.01)$. Across the sample, $79.1 \%$ of the cavities decreased in volume and $3.5 \%$ were stable in size [20].

Alghamdi et al. found a significant overall decrease in cavity volumes, from an average preoperative tumor volume of $16 \mathrm{~cm}^{3}$ to a cavity volume of $12.4 \mathrm{~cm}^{3}$ at one month $(\mathrm{p}=0.03)$ [2]. Across this sample, the average cavity volume reduction was $22.5 \%$ [2]. This study also found that within the early interval $(<21$ days), cavity size increased an average of $58.6 \%$ relative to the preoperative tumor volume, but decreased by $5 \%$ and $7 \%$ in the intermediate (21-41 days) and late (>42 days) intervals, respectively [2].

\section{Predictors of differing rates of cavity-size changes}

Regarding predictors of changes in cavity size, larger preoperative tumors and dural involvement were both found to be associated with greater decreases in volume [2]. In particular, Alghambdi et al. found that resection cavities of larger tumors $(\geqslant 3 \mathrm{~cm})$ had a greater volume reduction $(16.3 \%)$ than smaller tumors (5.7\%) at a median of 30 days after resection. Moreover, a greater proportion of the larger tumors vs. the smaller tumors showed considerable volume reduction: $72 \%$ of tumors that are $>3 \mathrm{~cm}$ decreased in size, while only $44 \%$ of tumors that are $<3 \mathrm{~cm}$ decreased in size [2].

Atalar et al. found compatible results, as cavities that were larger immediately after the surgery (tumors of $>4.2 \mathrm{~cm}^{3}$ ) had a decrease in volume by $35 \%$ while smaller cavities (tumors of $<4.2 \mathrm{~cm}^{3}$ ) actually increased in volume; these smaller cavities had an increase of $46 \%$ in volume within the first three days after surgery [15]. There was no significant change in cavity size for neither larger nor small cavities between the third day and 33rd day after surgery [15], which contrasts with the finding above of continued tumor size decrease even weeks after resection [2]. 
Larger tumor cavities being associated with a greater decrease in size was also seen by Jarvis et al. [21]. In this study, the authors found a $47 \%$ volume decrease in larger $(>3 \mathrm{~cm}$ ) cavities, a decrease of $25.8 \%$ for smaller $(2.1 \mathrm{~cm}-3 \mathrm{~cm})$ preoperative tumor cavities, and an increase of $56 \%$ in smaller $(<2 \mathrm{~cm})$ volume cavities at a median of 29.8 days after resection [21].

In contrast, Scharl et al. found that while, on average, all cavities across the sample decreased in size, smaller cavities tended to experience greater shrinkage. In other words, the initial cavity size was negatively correlated with the proportional cavity shrinkage between post-resection and planning MRI, which contrasts with the other findings that initial cavity size was positively correlated with cavity shrinkage $[2,15,20,21]$. In this study, the mean cavity size decreased over time from the immediate postoperative MRI to follow-up MRIs. The greatest reduction in cavity volume, an average of $-23.4 \%$, occurred between the immediate postoperative MRI and the SRS planning MRI (an average of 25 days; $\mathrm{p}=<0.01$ ). Across the entire sample, between the immediate postoperative MRI and planning MRI, the cavity volume decreased in $79.1 \%$ of the sample, remained stable in $3.5 \%$, and increased in $17.4 \%$ [20]. The mean percentage volume change over a median of 41 days was reflected as a reduction of $-28.5 \%$ for cavities with a volume $<10 \mathrm{~cm}^{3}$, and $-13.3 \%$ for cavities with a volume of $\geqslant 10 \mathrm{~cm}^{3}$ as measured in the first postoperative MRI.

Regarding possible mechanisms of the observed results, Wernicke et al. postulated that the majority of cavity shrinkage was largely due to the initial collapse of brain tissue into the resection cavity [19]. Ahmed et al. suggested that the observed early cavity volume change was mostly due to vasogenic edema [16]. Conversely, Jarvis et al. examined the MRIs of patients with cavity-volume increase given their unexpected results of the cavity size and found that, on average, cavities increase in size. The underlying reason behind the increase in the size of the 13 cavities was the progression of local disease in two patients, accumulation of fluid or blood products in 9 patients, and nonspecific postsurgical enhancement around the cavity in two patients [21]. The changes in resection cavity dynamics found in each study are summarized below (Table 1). 


\begin{tabular}{|c|c|c|c|c|c|c|c|c|}
\hline Reference & Study type & $\begin{array}{l}\text { Number } \\
\text { of } \\
\text { patients }\end{array}$ & $\begin{array}{l}\text { Number } \\
\text { of } \\
\text { resection } \\
\text { cavities }\end{array}$ & $\begin{array}{l}\text { Length of } \\
\text { cavity size } \\
\text { follow- up } \\
\text { (mean/longest) }\end{array}$ & $\begin{array}{l}\text { Early cavity-size } \\
\text { change (post-op } \\
\text { to Week 3) }\end{array}$ & $\begin{array}{l}\text { Intermediate } \\
\text { cavity-size } \\
\text { change } \\
\text { (week 3- } \\
\text { week 6) }\end{array}$ & $\begin{array}{l}\text { Late cavity-size } \\
\text { change (week 6- } \\
\text { later) }\end{array}$ & $\begin{array}{l}\text { Overall resection cavity-size } \\
\text { change as reported in the } \\
\text { study }\end{array}$ \\
\hline $\begin{array}{l}\text { Ahmed et } \\
\text { al., } 2014 \\
{[16]}\end{array}$ & Prospective & 37 & 39 & $1 \mathrm{~m} / 1 \mathrm{~m}$ & Shrinkage & Shrinkage & $\begin{array}{l}\text { No significant } \\
\text { change }\end{array}$ & $\begin{array}{l}58 \% \text { of cavities decreased in } \\
\text { volume }\end{array}$ \\
\hline $\begin{array}{l}\text { Alghamdi } \\
\text { et al., } \\
2018 \text { [2] }\end{array}$ & Prospective & 59 & 61 & $1 \mathrm{~m} / 3.6 \mathrm{~m}$ & $\begin{array}{l}\text { No significant } \\
\text { change }\end{array}$ & Shrinkage & $\begin{array}{l}\text { Smaller cavities: } \\
\text { shrinkage. Larger } \\
\text { cavities: no } \\
\text { significant } \\
\text { change }\end{array}$ & $\begin{array}{l}\text { Average cavity volume } \\
\text { reduction of } 22.5 \% \text {. }\end{array}$ \\
\hline $\begin{array}{l}\text { Atalar et } \\
\text { al., } 2012 \\
\text { [15] }\end{array}$ & Prospective & 63 & 68 & $20 \mathrm{~d} / 33 \mathrm{~d}$ & $\begin{array}{l}\text { No significant } \\
\text { change past day } 3 \\
\text { (days } 1-3 \text { had } \\
\text { significant } \\
\text { shrinkage) }\end{array}$ & $\begin{array}{l}\text { No } \\
\text { significant } \\
\text { change }\end{array}$ & $\begin{array}{l}\text { No significant } \\
\text { change }\end{array}$ & $\begin{array}{l}\text { Cavity volume did not change } \\
\text { significantly }\end{array}$ \\
\hline $\begin{array}{l}\text { Jarvis et } \\
\text { al., } 2012 \\
\text { [21] }\end{array}$ & Retrospective & 41 & 43 & $23.9 \mathrm{~d} / 104 \mathrm{~d}$ & Shrinkage & $\begin{array}{l}\text { No } \\
\text { significant } \\
\text { change }\end{array}$ & $\begin{array}{l}\text { No significant } \\
\text { change }\end{array}$ & $\begin{array}{l}20 \text { cavities }(46.5 \%) \text { were stable, } \\
10 \text { cavities }(23.3 \%) \text { decreased } \\
\text { in volume, } 13 \text { cavities }(30.2 \%) \\
\text { increased in volume }\end{array}$ \\
\hline $\begin{array}{l}\text { Scharl et } \\
\text { al., } 2018 \\
\text { [20] }\end{array}$ & Retrospective & 57 & 57 & $31 \mathrm{~d} / 122 \mathrm{~d}$ & Shrinkage & Shrinkage & Shrinkage & $\begin{array}{l}\text { Average cavity volume } \\
\text { reduction of } 23.4 \% .79 \% \text { of } \\
\text { cavities had decrease in volume }\end{array}$ \\
\hline $\begin{array}{l}\text { Shah et } \\
\text { al., } 2016 \\
{[18]}\end{array}$ & Retrospective & 21 & 21 & $41 \mathrm{~d} /$ Unknown & Shrinkage & Shrinkage & Shrinkage & $\begin{array}{l}90 \% \text { of cavities had a decrease } \\
\text { in volume }\end{array}$ \\
\hline $\begin{array}{l}\text { Wernicke } \\
\text { et al., } \\
2016 \text { [17] }\end{array}$ & Prospective & 30 & 30 & $\begin{array}{l}\text { Unknown/140 } \\
\text { d }\end{array}$ & Shrinkage & Shrinkage & Shrinkage & $\begin{array}{l}\text { Median cavity shrinkage of } \\
84.8 \%\end{array}$ \\
\hline
\end{tabular}

TABLE 1: Changes in resection cavity size in relation to time during the postoperative period m: months, d: days

\section{What is the optimal timing for the irradiation of large resected brain metastases with SRS?}

A number of studies have shown that the resection cavity volume decreases over time; however, the time at which the greatest decrease occurred differed somewhat between the findings [2,16-18,20-22]. Thus, in this section, we will examine the specific time points at which there was a significant volume change.

Alghambdi et al. found that larger tumor cavities decreased in volume, while small tumor cavities initially (within the first 21 days) increased in volume [2]. Over the entire sample, the cavities, on average, increased in size relative to the original tumor size by $59 \%$ within the first 21 days, decreased by $5 \%$ between $22-41$ days, and decreased by $11 \%$ after 42 days [2]. For small cavities, the authors found that the post-resection cavity was largest at the time of the immediate postoperative MRI and decreased at all follow-up time points for larger tumors, while cavity volume of the small tumors decreased after 21 or more postoperative days. They also found that large tumors showed a significant relative decrease in volume specifically during the intermediate postoperative period (between 22-42 postoperative days) [2].

In another study, Wernicke et al. found that postoperative resection cavities continuously decreased in size, when measured on day 1,30 days, and 90 days after surgery, respectively [17]. The cavity shrinkage between each of these time points was statistically significant (time point $1: \mathrm{p}=.002$; time point $2: \mathrm{p}=.001$; time point $3: \mathrm{p}=<.001$ ), indicating that the decrease in cavity size continued consistently throughout the threemonth period. 
Shah et al.'s findings supported this pattern of results: significantly greater constriction occurred for patients with a longer time between MRIs (mean 61\% reduction in volume) compared to those with an interval of $<1$ month between immediate postoperative MRI and planning MRI (13\% reduction in volume). Across the entire sample, the tumor cavity shrank by an average of $43 \%$ at a median of 41 days after the initial postoperative MRI.

While Scharl et al. and Ahmed et al. also found decreased cavity size over time, they suggested that the most significant cavity-size changes occurred in the earliest postoperative period, specifically within 31 days $[16,20]$. Atalar et al. also found that the most significant cavity shrinkage occurred early, but within an even shorter timeframe; they found that the majority of cavities changed volume within 3 postoperative days, but did not change significantly from 3-33 days [15].

Jarvis et al. found that nearly $50 \%$ of resection cavities did not significantly increase or decrease in volume (defined as a change of $\leqslant 2 \mathrm{~cm}^{3}$ ), while $23 \%$ showed cavity shrinkage and $30 \%$ showed cavity expansion [21]. The mean time between initial postoperative and pre-SRS scans was 24 days (range: 2-104). However, Jarvis et al. did not report the timing of cavity shrinkage; thus, it is not possible to ascertain when these changes in volume occurred [21]. However, the authors did state that for the patients that showed an increase in cavity size, the increase was greatest during the interval between the MRI-2 and MRI-3, which occurred at an average on day 19.1 after the surgery (range: 4-76 days) [21].

We present below a schematic of the changes in the postoperative cavity size for large and small tumors (Figure 1).

A

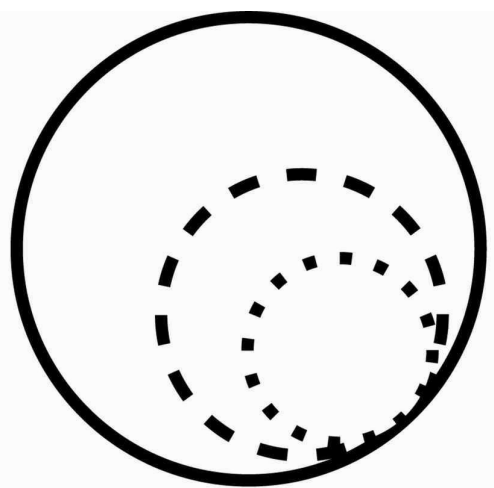

C

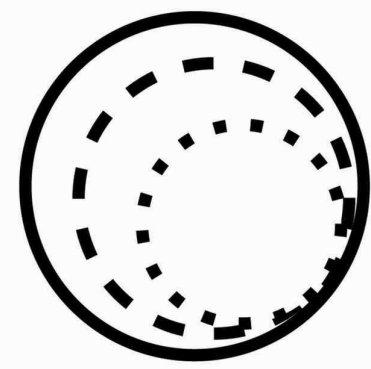

B

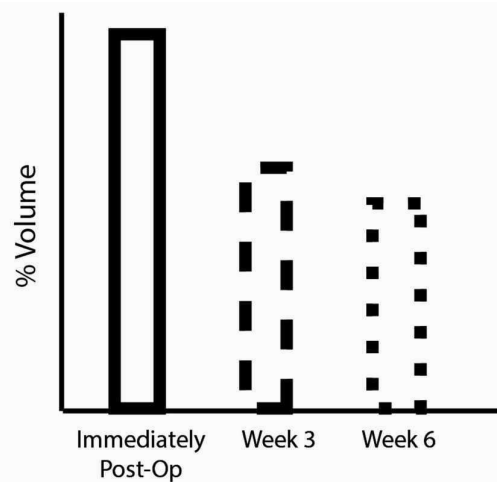

D

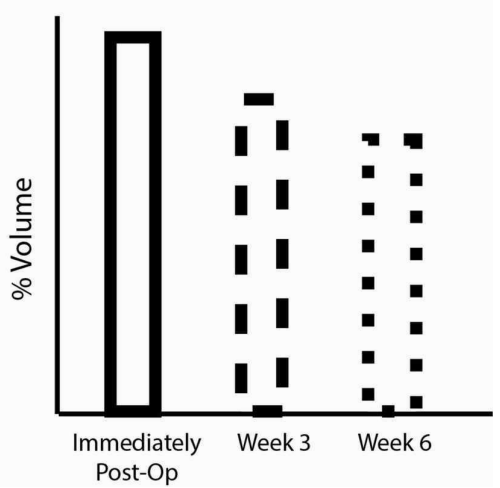

FIGURE 1: Schematic and estimated volume (\%) of cavity-size changes over time

A, B: large cavities ( $>3 \mathrm{~cm}$ in diameter); C, D: small cavities $(<3 \mathrm{~cm}$ in diameter)

\section{What are the causes of decreased local control with SRS?}

One factor that predicts worse LC with SRS vs. WBRT after resection is tumor size. Several studies have found a negative correlation between increasing preoperative tumor size and a significantly diminished rate of LC where treatment failure is more likely in larger tumors [22-24]. Preoperative tumor sizes of greater than $3 \mathrm{~cm}$ have been found to have reduced LC over a range of $40 \%$ to $\sim 70 \%$ [22,23]. 
The first prospective phase II trial that evaluated postoperative SRS found that preoperative tumors of $>3.0$ $\mathrm{cm}$ with superficial meningeal involvement, as well as infratentorial tumors, had higher rates of local failure [23]. Across the entire sample, the rate of local failure was $22 \%$ at a median follow-up of 12 months (range 194.1 months) [23]. Tumors of $>3 \mathrm{~cm}$ had a $39.1 \%$ rate of local failure, while tumors of $<3 \mathrm{~cm}$ had only a $7.5 \%$ rate of local failure at 12 months. As has been shown in other studies, meningeal involvement also predicted worse LC. In this study, the worst rates of LC were seen in large tumors $(>3 \mathrm{~cm})$ with superficial dural or pial involvement, with a $53.3 \%$ rate of local failure at 12 months [23].

Hartford et al.'s study, with a median follow-up of 9.3 months (range 1.1-61.4 months), also demonstrated that postoperative SRS led to decreased rates of LC in larger tumors vs. smaller tumors [23]. Univariate analysis found that preoperative tumor size of $>3 \mathrm{~cm}$ predicted a significantly shorter time to local recurrence, and that preoperative tumor size of $>2 \mathrm{~cm}$ also predicted a significantly shorter time to local recurrence, in addition to shorter time to distant recurrence and intracranial recurrence [23]. Lastly, Jensen et al. found on multivariate analysis that preoperative tumor diameter of $>3 \mathrm{~cm}$ was associated with a 13.6 times greater risk of local failure compared to patients with tumor diameters of $\leqslant 3 \mathrm{~cm}$ at one year [hazard ratio $(\mathrm{HR})=13.6, \mathrm{p}=0.012][25]$.

An earlier study had shown that while LC was achieved in 94\% of the sample using postoperative SRS, there were three cases of tumor recurrence at the surgical site [14]. Interestingly, the treated volumes for the resection cavities in these cases $\left(15.5,18.4\right.$, and $\left.21.1 \mathrm{~cm}^{3}\right)$ were significantly larger than the volumes treated in the remaining cavities, leading the authors to conclude that patients who underwent radiosurgery to larger resection cavities had a higher likelihood of tumor recurrence [14].

Even for SRS to the tumor without surgical resection, greater tumor volume predicts worse LC [26]. That is, a tumor volume of $\geqslant 2 \mathrm{~cm}^{3}$ significantly predicted worse LC on univariate analysis $(\mathrm{p}=<0.001)$. Local tumor control was $97 \%$ for lesions of $<2 \mathrm{~cm}^{3}$ at one year after SRS compared with $75 \%$ for lesions of $\geqslant 2 \mathrm{~cm}^{3}(\mathrm{p}=$ $<0.001)$. This was also demonstrated in an earlier study by Vogelbaum et al., which found that brain metastases larger than $2 \mathrm{~cm}$ were less effectively controlled than smaller tumors, though they did not report rates of local failure for different tumor sizes [27].

Another factor that is associated with worse LC by SRS is time between surgery and initiation of SRS. As noted, the volume of the tumor cavity can change significantly in the days and weeks after resection. Thus, if this change in volume is unaccounted for or incompletely accounted for as estimated by the most recent MRI before radiation treatment, rates of treatment failure increase [11,16,24,28]. This supports the findings that LC is worse with longer time between surgery and the initiation of treatment; that is, there is a greater risk of treatment failure with increasing delay after resection $[23,28,29]$, which is hypothesized to be in part due to changes in cavity dimensions.

One retrospective study of 103 resection cavities in 100 patients found that SRS performed more than three weeks after resection was associated with greater probability of local recurrence, leading the authors to recommend that SRS should be performed as early as possible after surgery [30]. In this study, the authors used univariate analysis to find that longer surgery-to-SRS delay is a risk factor for recurrence [HR: 1.625; 95\% confidence interval (CI): 1.183-2.231; $\mathrm{p}=0.003$ ]. They used Kaplan-Meier analysis to find that the maximum delay that best predicted LC was administering SRS within three weeks or earlier after surgery [30]. In this study, the overall rate of LC was $73 \%$ across the entire sample at 12 months. Stratifying this by time, the group of patients who received SRS less than three weeks after surgery had an $87 \%$ rate of LC at 12 months, while the group of patients who received SRS more than three weeks after surgery had a $61 \%$ rate of LC at 12 months [30]. This difference in rates of LC remained throughout follow-up; at 36 months, the group that received SRS less than three weeks after surgery had a $72 \%$ rate of LC compared to $46 \%$ for patients who received SRS more than three weeks after surgery [30].

A similar finding was replicated in another study by Strauss et al [28]. In this study, the overall LC rate was $84 \%$ at one year and $79 \%$ at two years [28]. As in the study by Iorio-Morin et al., Strauss et al. found that increasing delay between surgery and SRS was directly correlated with local failure using univariate log-rank regression on a sample of 102 brain metastasis cavities treated with postoperative SRS in 100 patients (HR: $1.46, p=0.02$ ) [28]. This study did not divide the patients into groups with differing times from surgery to SRS, using univariate regression instead. As a result, we do not have rates of LC for patients who received SRS more or less than three weeks after surgery for comparison to the previous study.

There is wide acceptance that radiation treatment to the resection cavity should not be unnecessarily delayed. However, there are different protocols between institutions as to the ideal time for SRS after surgery, with some groups recommending earlier than six weeks, and others recommending earlier than three weeks, with a general acceptance of around four weeks $[11,16,25,28,30]$. The Radiation Therapy Oncology Group (RTOG) has yet to provide exact guidelines regarding the optimal timing of postoperative SRS. However, a recent review recommends that based on current evidence, performing SRS within 2-3 weeks after surgery is the best option to allow the patient to recover surgically, without excessively delaying postoperative treatment [31]. This is based on recent evidence from Iorio-Morin et al. that a significant risk factor for decreased LC is a delay of greater than three weeks before surgery, and Patel et al., who found no 
significant cavity shrinkage after 2-3 weeks and concluded that SRS within 2-3 weeks is most appropriate $[30,32]$.

Based on the current evidence showing the unpredictability of the exact pattern of change in resection cavity size over time, we can conclude that obtaining a planning MRI as close in time to treatment as possible should be prioritized [21,25,31]. This was supported by Ahmed et al.'s findings that more patients became eligible for SRS with increasing follow-up time due to cavity shrinkage; Jarvis et al.'s results showing unpredictable rates of cavity volume increase or decrease during follow up; and the numerous other studies showing continuous cavity-volume decrease after surgery [18-20]. For example, in the study by Ahmed et al., four cavities were $>40 \mathrm{~mm}$ on the immediate postoperative MRI. A tumor cavity of this size is generally considered a poor candidate for SRS [16]. However, the authors found that because all four of these large cavities decreased to be below SRS threshold of $30 \mathrm{~mm}$ diameter within their follow up time, then rescanning of all cavities, but especially the ones closest to the treatment cut-off threshold, as close to the planned treatment date may allow for more patients to be eligible for SRS treatment [16]. As the majority of studies showed a continuous cavity-size decrease over time, this would indicate that obtaining a planning MRI closer to the date of treatment would perhaps allow for a lower total dose of radiation to be used, given a smaller volume to irradiate [18-20,28].

\section{Advantages and disadvantages of two focal radiation treatments}

It has been shown that both SRS and intraoperatively implanted brachytherapy seeds lead to good disease control and decreased likelihood of recurrence, as the postoperative adjuvant irradiation can eliminate the microscopic disease that remains in the resection cavity $[28,33,34]$. However, given the different dynamics for large vs. small resection cavities at different points in time, it is important to understand which focal radiation treatment might work best in specific situations. To this end, we will review the advantages and disadvantages of SRS and intraoperative brachytherapy with volume-based implants in the management of brain metastases.

SRS is a non-invasive method of administering focused, convergent beams to deliver a high dose of radiation to an area of interest. Brachytherapy is another increasingly popular method of providing local high-dose radiation but requires a neurosurgical procedure with intraoperative placement of radio-isotopes [35]. One important consideration in choosing SRS over brachytherapy is the size of the tumor cavity; a preoperative tumor diameter of less than $3 \mathrm{~cm}$ is the commonly accepted size for consideration of treatment with SRS [1]. This is because SRS has shown inferior rates of control to larger resected tumor cavities in multiple studies. One large retrospective study found that larger tumors, when treated with SRS, had a shorter time to recurrence and symptomatology than smaller tumors treated with SRS [23]. Another study found that a preoperative tumor diameter of $>3 \mathrm{~cm}$ predicted greater risk of local treatment failure [25]. This finding that SRS is less effective in establishing LC in larger tumors has been replicated numerous times [14,22,23].

Another reason that SRS is not deemed the best choice in larger tumors is the higher rate of radiation necrosis, which can occur in up to $37.8 \%$ of patients within one year, specifically after tumors of $>1.5 \mathrm{~cm}$ in diameter are treated with the procedure [36]. This is most likely due to larger tumor resection cavities increasing the radiation burden on surrounding normal tissue when SRS is implemented, thus increasing the risk of edema and necrosis [5]. Conversely, larger cavities treated with intraoperative cesium-131 (Cs-131) implants have demonstrated excellent LC [17,19]. Previous trials with iodine-125 brachytherapy have also demonstrated very good LC in both large and small resected tumor cavities [37,38]. Interestingly, multidose SRS (9Gy x 3) has also shown good LC of $93 \%$ at one year for large (>3 cm) brain metastases [39], although this has not been commonly replicated.

An advantage of SRS is that it has been shown to effectively treat multiple metastatic foci. While SRS can be used for up to three resection cavities of CNS metastases, brachytherapy generally has only been shown to be effective in one resection cavity [19,37]. However, an advantage of brachytherapy is that it can be more readily applied to irregularly shaped cavities, while SRS is most suited to round cavities [11,25].

One particular advantage recently documented with brachytherapy is that seeds can be implanted in such a way as to maintain cavity volume. Wernicke et al. implanted Cs-131 seeds with fibrin glue, and this maintained cavity volume, thus avoiding cavity-volume fluctuation [17]. Significantly, this decreased fluctuation led to less variation in the proximity of the radiation seeds to each other and to normal tissue, thus stabilizing dosage strength [17,35]. Brachytherapy such as Cs-131 is also advantageous over SRS in cases of recurrent brain metastases in brains that have already been irradiated, as repeat irradiation greatly increases the risk of radiation necrosis [36]. This is because brachytherapy has the advantage of a steep dose fall-off outside of the immediate area of the resection cavity, leading to less irradiation of normal tissue $[19,38]$. Also, it has been hypothesized that immediate implantation of brachytherapy seeds may improve LC by counteracting the tumor-cell proliferation and dissemination caused by the surgical manipulation of the microenvironment during resection [38]. We present an algorithm detailing situations in which different radiation techniques are preferable (Figure 2). 


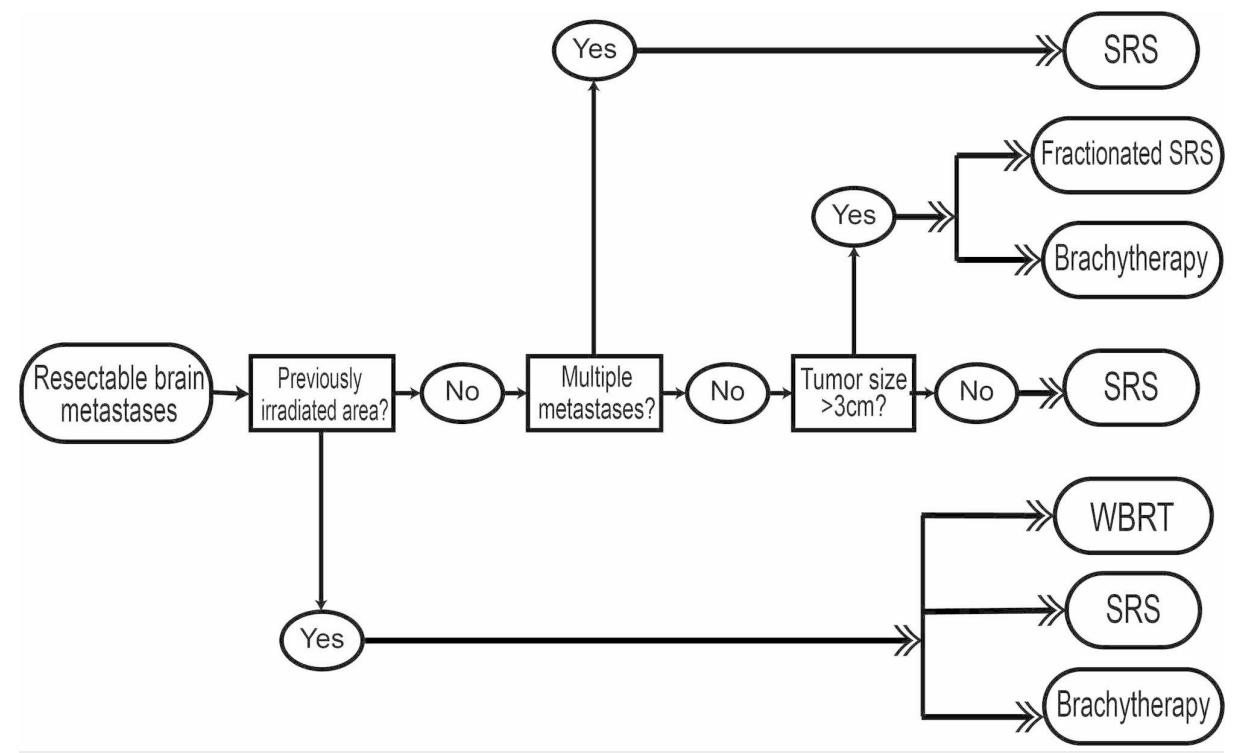

FIGURE 2: flow-chart algorithm detailing situations in which different radiation techniques are preferable

\section{Conclusions}

In conclusion, we have found that current evidence supports a general trend of cavity-site decrease after surgery, and larger tumor cavities generally have a greater average percent decrease compared to smaller cavities. To further apply this knowledge of cavity dynamics to treatment, we have reviewed two focal radiation treatments: SRS and brachytherapy. SRS is advantageous in smaller, more uniform tumor cavities, in addition to situations of multiple resection cavities, while intraoperative brachytherapy may be used for larger $(>3 \mathrm{~cm})$, more irregularly shaped tumor cavities. Our review also indicates that resection followed by SRS of smaller metastases is likely to benefit the patient; as the resection cavity shrinks, the volume of normal tissue that may be irradiated decreases. As it was shown that smaller resection cavities have a longer duration of decrease compared to larger tumors, it is possible that delaying radiosurgery on smaller metastases may be beneficial. We hope that this knowledge can be useful in deciding on the type and timing of post-resection radiosurgery for brain metastases.

\section{Additional Information}

\section{Disclosures}

Conflicts of interest: In compliance with the ICMJE uniform disclosure form, all authors declare the following: Payment/services info: All authors have declared that no financial support was received from any organization for the submitted work. Financial relationships: All authors have declared that they have no financial relationships at present or within the previous three years with any organizations that might have an interest in the submitted work. Other relationships: All authors have declared that there are no other relationships or activities that could appear to have influenced the submitted work.

\section{References}

1. Linskey ME, Andrews DW, Asher AL, et al.: The role of stereotactic radiosurgery in the management of patients with newly diagnosed brain metastases: a systematic review and evidence-based clinical practice guideline. J Neurooncol. 2010, 96:45-68. 10.1007/s11060-009-0073-4

2. Alghamdi M, Hasan Y, Ruschin M, et al.: Stereotactic radiosurgery for resected brain metastasis: cavity dynamics and factors affecting its evolution. J Radiosurgery SBRT. 2018, 5:191-200.

3. Brown PD, Jaeckle K, Ballman KV, et al.: Effect of radiosurgery alone vs radiosurgery with whole brain radiation therapy on cognitive function in patients with 1 to 3 brain metastases: a randomized clinical trial. JAMA. 2016, 316:401-9. 10.1001/jama.2016.9839

4. Chang EL, Wefel JS, Hess KR, et al.: Neurocognition in patients with brain metastases treated with radiosurgery or radiosurgery plus whole-brain irradiation: a randomised controlled trial. Lancet Oncol. 2009, 10:1037-44. 10.1016/S1470-2045(09)70263-3

5. Andrews DW, Scott CB, Sperduto PW, et al.: Whole brain radiation therapy with or without stereotactic radiosurgery boost for patients with one to three brain metastases: phase III results of the RTOG 9508 randomised trial. Lancet. 2004, 363:1665-72. 10.1016/S0140-6736(04)16250-8

6. Flickinger JC, Kondziolka D, Lunsford LD, et al.: A multi-institutional experience with stereotactic radiosurgery for solitary brain metastasis. Int J Radiat Oncol Biol Phys. 1994, 28:797-802. 10.1016/03603016(94)90098-1

7. Brown PD, Ballman KV, Cerhan JH, et al.: A phase III trial of post-operative stereotactic radiosurgery (SRS) 
compared with whole brain radiotherapy (WBRT) for resected metastatic brain disease. Int J Radiat Oncol Biol Phys. 2016, 96:937. 10.1016/j.ijrobp.2016.09.045

8. Kępka L, Tyc-Szczepaniak D, Bujko K, et al.: Stereotactic radiotherapy of the tumor bed compared to whole brain radiotherapy after surgery of single brain metastasis: results from a randomized trial. Radiother Oncol. 2016, 121:217-24. 10.1016/j.radonc.2016.10.005

9. Muacevic A, Kreth FW, Mack A, Tonn JC, Wowra B: Stereotactic radiosurgery without radiation therapy providing high local tumor control of multiple brain metastases from renal cell carcinoma. Minim Invasive Neurosurg. 2004, 47:203-8. 10.1055/s-2004-818511

10. Aoyama H, Shirato H, Tago M, et al.: Stereotactic radiosurgery plus whole-brain radiation therapy vs stereotactic radiosurgery alone for treatment of brain metastases: a randomized controlled trial. JAMA. 2006, 295:2483-91. 10.1001/jama.295.21.2483

11. Nieder C, Grosu AL, Gaspar LE: Stereotactic radiosurgery (SRS) for brain metastases: a systematic review . Radiat Oncol. 2014, Accessed: September 24, 2019: 10.1186/1748-717X-9-155

12. Kelly PJ, Lin YB, Yu AY, Alexander BM, Hacker F, Marcus KJ, Weiss SE: Stereotactic irradiation of the postoperative resection cavity for brain metastasis: a frameless linear accelerator-based case series and review of the technique. Int J Radiat Oncol Biol Phys. 2012, 82:95-101. 10.1016/j.ijrobp.2010.10.043

13. Muacevic A, Wowra B, Siefert A, Tonn JC, Steiger HJ, Kreth FW: Microsurgery plus whole brain irradiation versus Gamma Knife surgery alone for treatment of single metastases to the brain: a randomized controlled multicentre phase III trial. J Neurooncol. 2008, 87:299-307. 10.1007/s11060-007-9510-4

14. Jagannathan J, Yen CP, Ray DK, et al.: Gamma Knife radiosurgery to the surgical cavity following resection of brain metastases. J Neurosurg. 2009, 431:431-8. 10.3171/2008.11.JNS08818

15. Atalar B, Choi CYH, Harsh GR 4th, Chang SD, Gibbs IC, Adler JR, Soltys SG: Cavity volume dynamics after resection of brain metastases and timing of postresection cavity stereotactic radiosurgery. Neurosurgery. 2013, 72:180-5. 10.1227/NEU.0b013e31827b99f3

16. Ahmed S, Hamilton J, Colen R, et al.: Change in post-surgical cavity size within first 30 days correlates with extent of surrounding edema: consequences for postoperative radiosurgery. J Comput Assist Tomogr. 2014, 38:457-60. 10.1097/RCT.0000000000000058

17. Wernicke AG, Lazow SP, Taube S, et al.: Surgical technique and clinically relevant resection cavity dynamics following implantation of cesium-131 (Cs-131) brachytherapy in patients with brain metastases. Oper Neurosurg (Hagerstown). 2016, 12:49-60. 10.1227/NEU.0000000000000986

18. Shah JK, Potts MB, Sneed PK, Aghi MK, McDermott MW: Surgical cavity constriction and local progression between resection and adjuvant radiosurgery for brain metastases. Cureus. 2016, 8:e575. Accessed: September 24, 2019: 10.7759/cureus.575

19. Wernicke AG, Hirschfeld CB, Smith AW, et al.: Clinical outcomes of large brain metastases treated with neurosurgical resection and intraoperative cesium-131 brachytherapy: results of a prospective trial. Int J Radiat Oncol Biol Phys. 2017, 98:1059-68. 10.1016/j.ijrobp.2017.03.044

20. Scharl S, Kirstein A, Kessel KA, Duma MN, Oechsner M, Straube C, Combs SE: Cavity volume changes after surgery of a brain metastasis-consequences for stereotactic radiation therapy. Strahlenther Onkol. 2019, 195:207-17. 10.1007/s00066-018-1387-y

21. Jarvis LA, Simmons NE, Bellerive M, et al.: Tumor bed dynamics after surgical resection of brain metastases: implications for postoperative radiosurgery. Int J Radiat Oncol Biol Phys. 2012, 84:943-8. 10.1016/j.ijrobp.2012.01.067

22. Brennan C, Yang TJ, Hilden P, et al.: A phase 2 trial of stereotactic radiosurgery boost after surgical resection for brain metastases. Int J Radiat Oncol Biol Phys. 2014, 88:130-6. 10.1016/j.ijrobp.2013.09.051

23. Hartford AC, Paravati AJ, Spire WJ, et al.: Postoperative stereotactic radiosurgery without whole-brain radiation therapy for brain metastases: potential role of preoperative tumor size. Int J Radiat Oncol Biol Phys. 2013, 85:650-5. 10.1016/j.ijrobp.2012.05.027

24. Prabhu R, Shu H-K, Hadjipanayis C, et al.: Current dosing paradigm for stereotactic radiosurgery alone after surgical resection of brain metastases needs to be optimized for improved local control. Int J Radiat Oncol Biol Phys. 2012, 83:e61-66. 10.1016/j.ijrobp.2011.12.017

25. Jensen CA, Chan MD, McCoy TP, et al.: Cavity-directed radiosurgery as adjuvant therapy after resection of a brain metastasis. J Neurosurg. 2011, 114:1585-91. 10.3171/2010.11.JNS10939

26. Baschnagel AM, Meyer KD, Chen PY, et al.: Tumor volume as a predictor of survival and local control in patients with brain metastases treated with Gamma Knife surgery: clinical article. J Neurosurg. 2013, 119:1139-44. 10.3171/2013.7.JNS13431

27. Vogelbaum MA, Angelov L, Lee SY, Li L, Barnett GH, Suh JH: Local control of brain metastases by stereotactic radiosurgery in relation to dose to the tumor margin. J Neurosurg. 2006, 104:907-12. 10.3171/jns.2006.104.6.907

28. Strauss I, Corn BW, Krishna V, et al.: Patterns of failure after stereotactic radiosurgery of the resection cavity following surgical removal of brain metastases. World Neurosurg. 2015, 84:1825-31. 10.1016/j.wneu.2015.07.073

29. Yusuf MB, Amsbaugh MJ, Burton E, et al.: Increasing time to postoperative stereotactic radiation therapy for patients with resected brain metastases: investigating clinical outcomes and identifying predictors associated with time to initiation. J Neurooncol. 2018, 136:545-53. 10.1007/s11060-017-2679-2

30. Iorio-Morin C, Masson-Côté L, Ezahr Y, Blanchard J, Ebacher A, Mathieu D: Early gamma knife stereotactic radiosurgery to the tumor bed of resected brain metastasis for improved local control: clinical article. J Neurosurg. 2014, 121:69-74. 10.3171/2014.7.GKS141488

31. Marchan EM, Peterson J, Sio TT, et al.: Postoperative cavity stereotactic radiosurgery for brain metastases . Front Oncol. 2018, 8:342. Accessed: September 24, 2019: 10.3389/fonc.2018.00342

32. Patel RA, Lock D, Helenowski IB, Chandler JP, Sachdev S, Tate MC, Kruser TJ: Postsurgical cavity evolution after brain metastasis resection: how soon should postoperative radiosurgery follow?. World Neurosurg. 2018, 110:e310-14. 10.1016/j.wneu.2017.10.159

33. Mathieu D, Kondziolka D, Flickinger JC, et al.: Tumor bed radiosurgery after resection of cerebral metastases. Neurosurgery. 2008, 62:817-23. 10.1227/01.neu.0000316899.55501.8b 


\section{Cureus}

34. Patchell RA: The management of brain metastases . Cancer Treat Rev. 2003, 29:533-40. 10.1016/S03057372(03)00105-1

35. Xia Y, Mashouf LA, Baker BR, et al.: Outcomes of metastatic brain lesions treated with radioactive cs-131 seeds after surgery: experience from one institution. Cureus. 2018, 10:e3075. Accessed: September 24, 2019: 10.7759/cureus.3075

36. Kohutek ZA, Yamada Y, Chan TA, et al.: Long-term risk of radionecrosis and imaging changes after stereotactic radiosurgery for brain metastases. J Neurooncol. 2015, 125:149-56. 10.1007/s11060-015-1881-3

37. Ruge MI, Suchorska B, Maarouf M, Runge M, Treuer H, Voges J, Sturm V: Stereotactic 125 iodine brachytherapy for the treatment of singular brain metastases: closing a gap? Neurosurgery. 2011, 68:120918. 10.1227/NEU.0b013e31820b526a

38. Vargo JA, Sparks KM, Singh R, Jacobson GM, Hack JD, Cifarelli CP: Feasibility of dose escalation using intraoperative radiotherapy following resection of large brain metastases compared to post-operative stereotactic radiosurgery. J Neurooncol. 2018, 140:413-20. 10.1007/s11060-018-2968-4

39. Minniti G, Esposito V, Clarke E, et al.: Multidose stereotactic radiosurgery $(9 \mathrm{~Gy} \times 3)$ of the postoperative resection cavity for treatment of large brain metastases. Int J Radiat Oncol Biol Phys. 2013, 86:623-9. 10.1016/j.ijrobp.2013.03.037 